\title{
Network analysis of bicyclo[3.3.1]nonanes: the diol, the dione and the acetal
}

Carl-Johan Wallentin ${ }^{a}$, Edvinas Orentas $^{b}$, Magnus T. Johnson ${ }^{a}$, Eugenijus Butkus ${ }^{*}{ }^{b}$, Ola F. Wendt* ${ }^{* a}$, Lars Öhrström*c ${ }^{*}$, and Kenneth Wärnmark*a

Received (in XXX, XXX) 1st January 2007, Accepted 1st January 2007

First published on the web 1st January 2007

DOI: $10.1039 / b 000000 x$

The solid state structure of endo,endo-bicyclo[3.3.1]nonane-2,6-diol, rac-2, shows a hydrogen bonded, three-connected, chiral 3D-net with utg-topology, distinctively different from those formed by the so called tubuland diols, i.e 2,6-

dimethylbicyclo[3.3.1]nonane-exo-2,exo-6-diol rac-5, that crystallise as threeconnected, chiral eta-nets and from the qtz-net formed by weaker hydrogen bonds in the bicyclo[3.3.1] nonane-2,6-dione, 3. The protected bicyclo[3.3.1]nonane-2,6-dione, bis-2,6-ethylenedioxy acetal $\mathbf{4}$, has a structure governed by weaker forces and can be interpreted as close packed stacks. 
Moderate size rigid hydrocarbons with a diol functionality tend to have solid state structures dominated by $\mathrm{OH} \ldots \mathrm{OH}$ hydrogen bonds. In some respect, the supramolecular chemistry of these systems commences by the structure 5 determination of 1,3-dihydroxybenzene in $1936,{ }^{1}$ the introduction of network analysis by Wells in $1954^{2}$ and his subsequent determination of the topology of this structure as $(10,3)$-d, or with contemporary nomenclature, ${ }^{3}$ utp-net. ${ }^{4}$

The bicyclo[3.3.1]nonanes (scheme 1) are geometrically 10 more complex than a benzene ring, as, for example, the bicyclic system may be chiral by virtue of its substitution pattern. A further characteristic of this framework is the conformational mobility of the two cyclohexane rings adopting chair or boat conformations. ${ }^{5}$

15 The exploitation of this hydrocarbon backbone, a common motif in many biologically active compounds and their metabolites, in stereo- and enantioselective reactions has been reviewed recently. ${ }^{6}$

20 Scheme 1. The bicyclo[3.3.1]nonane skeleton showing both the boat and chair conformation, $\mathbf{1}$, schematic drawings of the compounds presented in this work; 2-4 and one of Bishop's "tubuland diols" rac-5.

Not surprisingly, the unique molecular shape of the bicyclo[3.3.1]nonane framework has been used to form self-

${ }_{25}$ assembled supramolecular structures and inclusion complexes with various guest molecules. ${ }^{7,8}$ Some derivatives of this ring skeleton, the so called "tubuland diols", give controllable crystal structures with a variety of inclusion guests, an impressive feat of crystal engineering. ${ }^{9}$

30 In this communication we present the solid state structures of the bicyclo[3.3.1]nonane derivatives 2-4, and in particular the network analysis of the supramolecular 3D-nets formed. We have also applied this network approach to Bishop's tubuland diols, exemplified by the racemic 2,635 dimethylbicyclo[3.3.1]nonane-exo-2,exo-6-diol (rac-5) forming enantiomorphic crystals of $\mathbf{5}$, and suggest that this is an appropriate method to analyse these systems in general.

\section{Results and discussion}

\section{Synthesis and crystal growth}

40 All compounds were prepared according to published procedures. ${ }^{10}$ Crystals were grown by slow evaporation or by cooling. Attempts to grow suitable single crystals of the optically pure diprotected keton, (+)-4, were unsuccessful because of its high solubility in all solvents explored, also at 45 low temperature.

\section{Structures and network analysis}

All intra-molecular bonds and angles are normal and will not be commented further on. Hydrogen bonds and close contacts for all structures are summarised in Table 1, and we will now ${ }_{50}$ explore each structure in it turn.
Table 1 Hydrogen bonds and close contacts ( $\AA$ and deg) for 2-4

$\begin{array}{cccccc}\text { Compound } & & \text { D-H } & \text { A...H } & \text { D...A } & \\ \mathbf{2} & \text { O1--H1..O2_a } & 0.82 & 1.96 & 2.78 & 175 \\ \mathbf{2} & \text { O2--H2...O1_b } & 0.82 & 2.00 & 2.82 & 174 \\ \mathbf{3} & \text { C5--H5A...O1_c } & 0.97 & 2.52 & 3.40 & 150 \\ \mathbf{3} & \text { C5--H5B...O1_d } & 0.97 & 2.52 & 3.40 & 150 \\ \mathbf{4} & \text { C17--H17A...O3_e } & 0.97 & 2.72 & 3.58 & 148 \\ \mathbf{4} & \text { C12--H12B...O1_f } & 0.97 & 2.73 & 3.55 & 143\end{array}$

Symmetry codes: $a=1-y,-x, 1 / 2-z, b=-1 / 2+x, 1 / 2-y, 3 / 4-z, c=x-y, 1-y,-$ $\mathrm{z}, \mathrm{d}=\mathrm{x}-\mathrm{y},-1+\mathrm{x}, 1 / 6+\mathrm{z}, \mathrm{e}=\mathrm{x},-1+\mathrm{y}, \mathrm{z}, \mathrm{f}=1-\mathrm{x},-\mathrm{y},-\mathrm{z}$

55

endo,endo-bicyclo[3.3.1] nonane-2,6-diol 2

The endo,endo-bicyclo[3.3.1]nonane-2,6-diol crystallise in the chiral space group $\mathrm{P} 4{ }_{1} 2{ }_{1} 2$, and thus forms a conglomerate ${ }_{60}$ by spontaneous resolution. In the so formed enantiomorphs each hydroxyl group participates in intermolecular hydrogen bonds as both donor and acceptor so that each oxygen can be regarded as a node in a three-connected, 3D-net, schematically shown in Figure 1.

65

Figure 1. Schematic representation of the hydrogen bonding and nodes in the 3D-network in the enantiomorphic endo,endo-bicyclo[3.3.1]nonane2,6-diol 2.

These hydrogen bonds define helices that are 70 interconnected by longer intramolecular links, and the complete net, (see Figure 2) has the unusual $\left(8^{2} .12\right)$-utg topology, which has no known examples in any compilations or databases to date. ${ }^{11-13}$

. This net is built from 8- and 12-rings, and is inherently 75 chiral, just as the more common srs-net (aka $(10,3)$-a).

Figure 2. The utg-net in enantiomorphic 2. Red links are hydrogen bonds and Grey links are intramolecular connections. The latter are much longer. $\mathrm{C}-\mathrm{C}$ bonds have been dashed and hydrogen atoms have been 80 omitted for clarity.

Possibly, the large bulk of the bicyclic ring system prevents any of the common ${ }^{12,13}$ three-connected nets to form. The fact that $\mathrm{rac}-\mathbf{2}$ crystallises as enantiomorphs makes it more likely that it will form a chiral net. However, there are many chiral 85 three-connected nets, 16 of which can be found in the Reticular Chemistry Structural Resource database. ${ }^{3,14}$

Contrary to the case of the tubuland diols, that seem to crystallise as enantiomorphs in general, there are no voids or channels in enantiomorphic 2. As the former are also reported 90 to form 3D-networks, ${ }^{9}$ it seemed essential to establish that these networks are indeed different. Thus we performed the same network analysis on the previously reported enantiomorphic crystal structure of $\mathbf{5}$ as a chloroacetic acid clathrate $^{8}\left(\mathrm{CSD}^{15}\right.$ ref code ZAZSOI) as a representative of this ${ }_{95}$ class of diols.

Network analysis of 2,6-dimethylbicyclo[3.3.1]nonane-exo2,exo-6-diol 5

The hydrogen bond pattern and nodal assignment is 100 identical to that of enantiomorphic 2 (Figure 1), but the 3D net formed is different, an $\left(8^{3}\right)$-eta-net (see Figure 3 ), described by Wells as $(8,3)-\mathrm{a}^{16}$. This net too is intrinsically 
chiral, but less dense by $27 \%$ compared to the utg-net, ${ }^{14}$ thus explaining the tendency of the tubuland diols to form inclusion compounds.

We want to emphasize that our analysis does not invalidate ${ }_{5}$ the conclusions in ref. 9 concerning the molecular origin of the clathrate structures, it rather compliments these discussion. A key issue discussed by these authors and exploited in their synthetic chemistry, is the relative orientation of the hydroxyl groups. Note that this is different 10 in $\mathbf{2}$ and $\mathbf{5}$ and ultimately responsible for the different networks formed. In addition to the exo,exo relationship between the hydroxyl groups the bulkiness of the alkyl substituents at position 2 and 6 are of crucial importance for the formation of porous network structures. Apparently, only 15 methyl groups have the right structural features to give tubular inclusion compounds.

It should also be mentioned that the chloroacetic acid in this structure is disordered and no specific interactions with the framework therefore can be detected. Moreover, 5 ${ }_{20}$ consistently form these types of inclusion network compounds all apparently having the same topology.

Figure 3. The eta-net in enantiomorphic $\mathbf{5}^{8}$. Red links are hydrogen bonds and grey links are the longer intramolecular connections. $\mathrm{C}-\mathrm{C}$ bonds are 25 dashed and hydrogen atoms omitted for clarity. The large channels contain disordered chloroacetic acid (not shown).

\section{bicyclo[3.3.1]nonane-2,6-dione 3}

The asymmetric unit in the structure of 3 contains half a molecule and the twofold axis through C5 generates the whole 30 molecule. Concerning the crystal structure it poses a somewhat different problem: While it is clear that strong hydrogen bonds are the dominant forces in $\mathbf{2}$ and $\mathbf{5}$, it is not so clear if the weaker C-O...H-C interactions in $\mathbf{3}$ and $\mathbf{4}$ will have the same influence and thus if a network approach is a 35 profitable way of looking at these structures.

However, we have recently explained the unexpected formation of large channels and other motifs in organometallic [2,6-Bis[(di-t-butylphosphino)methyl]phenyl] palladium(II) compounds by weak hydrogen bonds, ${ }^{17}$ and thus ${ }_{40}$ deemed the method worth a try also in this case.

We can get some idea of what to expect from the known structure of racemic $3,{ }^{18}$ where weak hydrogen bonds (CH...O: $\left.2.62 \AA, \quad 3.44-3.49 \AA, 131-144^{\circ}\right)$ connect these molecules into chains that are then packed in parallel (vide ${ }_{45}$ infra, Figure 6). These chains are not possible with one enantiomer only, indeed even the dimer cannot form. Consequently, the optically pure crystals from (+)-3 adopt a very different structure with every molecule forming weak $\mathrm{C}$ H...O hydrogen bonds (C5-H5A...O1*: $2.52 \AA$, 3.401(2) $\AA$, so $150^{\circ}$ ) to four other molecules, [where $\mathrm{O} 1^{*}$ is the $\mathrm{O} 1$ atom at $(y,-1+x, 1 / 3-z)]$ see Figure 4 , giving a net with $\left(6^{4} \cdot 8^{4}\right)-\mathbf{q t z}$ (quartz) topology, see Figure 5.

Figure 4. Displacement ellipsoid plot (50\%) showing the four weak hydrogen bonds connecting each (+)-3 dione to four neighbours. Symmetry codes for the weak hydrogen bonds are given in Table 1 .

The qtz-net is also inherently chiral, and is the most common of the chiral four-connected nets, so this has a certain logic. In contrary to what was found for the qtz-net in 60 [2,6-Bis[(di-t-butylphosphino)methyl]phenyl] palladium(II) nitrite, formed by $\mathrm{NO}_{2} \ldots \mathrm{H}-\mathrm{C}$ weak hydrogen bonds ${ }^{17}$ there are no solvent molecules present in this structure, and no voids were found by PLATON ${ }^{19}$.

Note, however, that a net formation does not necessarily ${ }_{65}$ mean that the interactions in homochiral $\mathbf{3}$ are stronger than in the crystal consisting of racemic-3. To the contrary, the density and melting point of the latter is higher $\left(1.302 \mathrm{~g} / \mathrm{cm}^{3}\right.$, $\left.141^{\circ} \mathrm{C}\right)$ than for the optically pure material $\left(1.222 \mathrm{~g} / \mathrm{cm}^{3}\right.$, $132^{\circ} \mathrm{C}$ ), indicating stronger intermolecular interactions in the 70 in the crystals of racemic 3.

Tentatively, one may argue that if we attribute the higher stability of rac-3 to stronger van der Waals forces, then the weaker interactions that hold the crystals of (+)-3 together have relatively less of these non-directional forces and, 75 consequently, the weak hydrogen bonds may play a larger role for the overall structure.

Figure 5. The four-connected chiral qtz-net in $\mathbf{3}$ shown in red. Nodes are placed in the centroids of the bicyclonoane and the network is built up 80 from weak C-H...O hydrogen bonds. C-C bonds are dashed and hydrogen atoms have been omitted for clarity. The apparent channels have no effective voids.

\section{bis-2,6-ethylenedioxy acetal bicyclo[3.3.1]nonane 4}

One would expect the acetal protected dione 4 (IUPAC name 85 bicyclo[3.3.1] nonane-1-spiro-2'-dioxolane-6-spiro-2''-

dioxolane) to have lesser tendencies to act as a hydrogen-bond acceptor because of steric crowding. On the other hand, an ether (as model of an acetal) is a stronger base $\left(\mathrm{pK}_{\mathrm{aH}} \approx-4\right)$ compared to a diketone $3\left(\mathrm{pK}_{\mathrm{aH}} \approx-7\right) .{ }^{20}$ In a combined CSD 90 and computational study their hydrogen bonding ability has been judged to be equal, ${ }^{21}$ but we need also to consider the effect of two oxygens bonded to the same carbon in an acetal, so the overall effect is hard to estimate $a$ priori.

However, analysing the crystal structure we find no 95 intermolecular O...H contacts shorter than $2.72 \AA$, indicating considerably weaker (or even non-existent), hydrogen bond interactions than in $\mathbf{3}$. Whatever interactions there are seem to assemble 4 in oblong stacks that are more or less close packed, with a closest $\mathrm{O} \ldots \mathrm{H}$ contact at: C17-H17A...O3* ( $1002.72 \AA, 3.582(2) \AA, 148^{\circ}$ with O3* at $\left.(\mathrm{x}, \mathrm{y}-1, \mathrm{z})\right)$, somewhat resembling the packing of the weak hydrogen bonded chains in the crystal structure of rac-3 containing heterochiral $3^{18}$. The two structures are compared in Figure 6.

105 Figure 6. Close-packing of the one-dimensional motifs in racemic crystals of both $\mathbf{3}^{18}$ and $\mathbf{4}$, respectively ( $\mathrm{H}=$ green, $\mathrm{C}=$ black, $\mathrm{O}=$ red)

\section{Conclusions}

Network analysis provides a good way of both understanding and comparing different hydrogen bonded diol crystal 110 structures (enantiomorphic $\mathbf{2}$ and $\mathbf{5}$ ), and may be profitable also for systems with weaker hydrogen bonds ((+)-3). However, its importance should not be exaggerated; closepacking motifs (non-directional dispersion forces etc) are 
probably important in the majority of structures with molecules having a dominant hydrocarbon backbone (rac-3 and rac-4).

\section{Experimental part}

\section{${ }_{5}$ Materials and preparations}

Compounds 2-4 were prepared according to published procedures. ${ }^{10}$ Compound $\mathrm{rac}-2$ was dissolved in hot acetone to obtain a saturated solution. Crystals were obtained by keeping the solution at $4{ }^{\circ} \mathrm{C}$ over night. Crystals of (+)-3 10 suitable for $\mathrm{X}$-ray diffraction analysis were obtained by slow evaporation of a solution in petroleum ether $\left(40-60^{\circ} \mathrm{C}\right)$ and EtOAc (2:1). Crystals of rac-4 were obtained by slow evaporation of its solutions in petroleum ether $\left(40-60{ }^{\circ} \mathrm{C}\right)$.

$\underline{\text { Table } 2 \text { Parameters for data collection and structure refinement of } \mathbf{1} \text { and } \mathbf{2}}$

\begin{tabular}{|c|c|c|c|}
\hline & 2 & 3 & 4 \\
\hline Chemical formula & $\mathrm{C}_{9} \mathrm{H}_{16} \mathrm{O}_{2}$ & $\mathrm{C}_{9} \mathrm{H}_{12} \mathrm{O}_{2}$ & $\mathrm{C}_{13} \mathrm{H}_{20} \mathrm{O}_{4}$ \\
\hline Formula weight & 156.22 & 152.19 & 240.29 \\
\hline Crystal system & tetragonal & hexagonal & monoclinic \\
\hline Space group & $\mathrm{P} 4_{1} 2_{1} 2$ & $\mathrm{P} 6,22$ & $\mathrm{P} 2_{1} / \mathrm{n}$ \\
\hline$a / \AA$ & $9.9192(4)$ & $6.9851(4)$ & $11.4565(6)$ \\
\hline$b / \AA$ & $9.9192(4)$ & $6.9851(4)$ & $7.9243(4)$ \\
\hline$c / \AA ̊$ & $17.2456(12)$ & $29.362(3)$ & $13.7482(8)$ \\
\hline$\beta /^{\circ}$ & & & $106.287(6)$ \\
\hline Volume $/ \AA^{3}$ & $1696.80(15)$ & $1240.68(17)$ & $1198.04(11)$ \\
\hline$Z$ & 8 & 6 & 4 \\
\hline$\rho_{\text {calc }} / \mathrm{Mg} \mathrm{m}^{-3}$ & 1.223 & 1.222 & 1.332 \\
\hline$\mu / \mathrm{mm}^{-1}$ & 0.084 & 0.085 & 0.097 \\
\hline $\begin{array}{l}\text { No. of reflections } \\
\text { collected }\end{array}$ & 10328 & 3972 & 7626 \\
\hline $\begin{array}{l}\text { No. of independent } \\
\text { reflections }\end{array}$ & 934 & 513 & 2187 \\
\hline$\theta$ range ${ }^{\circ}$ & $2.37-25.03$ & $3.37-24.99$ & $2.72-25.34$ \\
\hline $\mathrm{R}$ (int) & 0.0651 & 0.0454 & 0.0367 \\
\hline No. of parameters & 102 & 51 & 154 \\
\hline Goodness-of-Fit & 1.153 & 1.018 & 1.049 \\
\hline $\mathrm{R} 1(I>2 \sigma(I))$ & 0.0376 & 0.0368 & 0.0428 \\
\hline wR2 (all data) & 0.1156 & 0.0842 & 0.1206 \\
\hline
\end{tabular}

\section{X-ray Crystallography}

Intensity data were collected at $293 \mathrm{~K}$ with an Oxford Diffraction Xcalibur 3 system using $\omega$-scans and Mo-K $\alpha(\lambda=$ $0.71073 \AA) .{ }^{22}$ CCD data were extracted and integrated using ${ }_{20}$ Crysalis RED. ${ }^{23}$ The structures were solved using direct methods and refined by full-matrix least-squares calculations on $\mathrm{F}^{2}$ using SHELXTL 5.1. ${ }^{24}$ Non-H atoms were refined with anisotropic displacement parameters. Hydrogen atoms were constrained to parent sites, using a riding model. For ${ }_{25}$ compounds $\mathbf{2}$ and $\mathbf{3}$ there is choice of either of two enantiomorphic space groups and since anomalous dispersion cannot be used to distinguish the two alternatives (given the wavelength and unit cell contents) we arbitrarily chose the one based on a 4(1) and 6(1) screw axis, respectively. Crystal

30 data and details about data collection are given in Table 2. All crystallographic data are available in CIF format, see http:|xxxx. CCDC reference numbers 717098, 722432 and 722431 .

\section{Network analysis}

35 Abbreviations (three-letter codes) for 3D nets were taken from the web-based Reticular Chemistry Structure Resource, where crystallographic coordinates and other useful details for 3Dnets can be obtained. ${ }^{14}$ The topology of the nets were established by computing the vertex symbol (extended ${ }_{40}$ Schläfli or long symbol ${ }^{25}$ with TOPOS ${ }^{26 a, b}$, OLEX ${ }^{26 c}$ or SYSTRE $^{26 \mathrm{~d}}$ and comparing both the symbol and the experimental net with the ideal net as well as with the automatic assignment by TOPOS.

\section{Acknowledgements}

${ }_{45}$ This work was supported by Nordforsk via the Nordic-Baltic Network in Crystal Engineering and Supramolecular Materials. We thank the Knut and Alice Wallenberg Foundation for funding the diffractometer.

\section{Notes and references}

${ }_{50}{ }^{a}$ Address, Organic Chemistry, Department of Chemistry, Lund University, P. O. Box 124, SE-221 00 Lund, Sweden. Fax: +4646 2228209; Tel: 4646222 0000; E-mail: ola.wendt@organic.lu.se, CarlJohan.Wallentin@organic.lu.se,Kenneth.Warnmark@organic.lu.se ${ }^{b}$ Address, Dept Organic Chemistry, Naugarduko 24, Vilnius 03225, 55 Lithuania. Fax: +370-5-2330987; Tel: +370-682-63092; E-mail: edvinas.orentas@chf.vu.lt,Eugenijus.Butkus@chf.vu.lt,

${ }^{c}$ Address, Dept. of Chemical and Biological Engineering, Chalmers University of Technology, SE-41296 Göteborg, Sweden. Fax: +46 31772 3858; E-mail: ohrstrom@chalmers.se,

$60 \dagger$ Electronic Supplementary Information (ESI) available: Additional structural data for 2-4. See DOI: 10.1039/b000000x/

1. J. M. Robertson, Proc. Roy. Soc (A), 1936, 157, 79.

65 2. A. F. Wells, Acta Cryst., 1954, 7, 535-544.

3. M. O'Keeffe, M. A. Peskov, S. Ramsden and O. M. Yaghi, Acc. Chem. Res., 2009, 41, 1782-1789.

4. A. F. Wells, Acta Cryst., 1954, 7, 842-848.

5. N. S. Zefirov, Usp. Khim., 1975, 44, 413-443. Russ. Chem. Rev.

70 (Engl. Transl.), 1975, 44, 196-211

6. E. Butkus, Synlett, 2001, 1827-1835.

7. (a) A. T. Ung, R. Bishop, D. C. Craig, I. G. Dance and M. L. Scudder, Chem. Mat., 1994, 6, 1269-1281; 7. b) S. Stončius, E. Butkus, A. Žilinskas, K. Larsson, L. Öhrström, U. Berg and K.

75 Warnmark, J. Org. Chem., 2004, 69, 5196-5203; (c) S. Stončius, E. Orentas, E. Butkus, L. Öhrström, O. F. Wendt and K. Wärnmark, J. Am. Chem. Soc., 2006, 128, 8272-8285; (d) V. T. Nguyen, R. Bishop, D. C. Craig and M. L. Scudder, Supramol. Chem., 2001, 13, 103-107.

80 8. A. T. Ung, D. Gizachew, R. Bishop, M. L. Scudder, I. G. Dance and D. C. Craig, J. Am. Chem. Soc., 1995, 117, 8745-8756.

9. R. Bishop, Acc. Chem. Res., 2009, 42, 67-78.

10. (a) C. J. Wallentin, E. Orentas, E. Butkus and K. Wärnmark, Synthesis, 2009, 864-867; (b) E. Orentas, G. Bagdžiūnas, U. Berg, A. Žilinskas and E. Butkus, Eur. J. Org. Chem., 2007, 4251-4256; (c) E. Beckmann, N. Bahr, O. Cullmann, F. Yang, M. Kegel, M. Vogtle, K. Exner, M. Keller, L. Knothe and H. Prinzbach, Euro. J. Org. Chem., 2003, 4248-4264; (d) J. P. Schaefer and L. M. Honig, J. Org. Chem., $1968,33,2655-2659$.

90 11. (a) N. W. Ockwig, O. Delagado-Friedrichs, M. O'Keeffe and O. M. Yaghi, J.Am.Chem.Soc., 2005, 38, 176-182; (b) V. A. Blatov and M. V. Peskov, Acta Cryst. Sec. B, 2006, 62, 457-466; (c) V. A. Blatov, L. Carlucci, G. Giani and D. M. Proserpio, Cryst. Eng. Comm., 2004, 
6, 377-395; (d) S. R. Batten, D. R. Turner and M. S. Neville, Coordination Polymers: Design, Analysis and Application, RSC, Cambridge, 2009.

12. I. A. Baburin, V. A. Blatov, L. Carlucci, G. Ciani and D. M. Proserpio, Cryst. Growth Des., 2008, 8, 519-539.

13. (a) L. Öhrström and K. Larsson, Dalton Trans., 2004, 3, 347-353; (b) L. Öhrström and K. Larsson, Molecule-Based Materials The Structural Network Approach, Elsevier, Amsterdam, 2005.

14. Reticular Chemistry Structure Resource, M. O'Keeffe, O. M. Yaghi

10 and S. Ramsden, Australian National University Supercomputer Facility, , http://rcsr.anu.edu.au/, 2009/, 2008

15. F. H. Allen, Acta Cryst. B, 2002, 58, 380-388.

16. A. F. Wells, Three-dimensional nets and polyhedra, John Wiley \& Sons, New York, 1977.

15 17. R. Johansson, L. Öhrström and O. F. Wendt, Cryst. Growth \& Design, 2007, 7, 1974-1979.

18. H. Quast, C. Becker, E. Geissler, K. Knoll, E. M. Peters, K. Peters and H. G. Vonschnering, Liebigs Ann., 1994, 109-120.

19. A.L. Speck, "PLATON, a multipurpose crystallographic tool."

20 Utrecht University, Utrecht, The Netherlands, 2001, http://www.cryst.chem.uu.nl/platon/.

20. J. Clayden, N. Greeves, S. Warren and P. Wothers, Organic Chemistry, Oxford University Press, Oxford, 2000.

21. J. P. M. Lommerse, S. L. Price and R. Taylor, J. Comput. Chem., 1997, 18, 757-774.

22. Crysalis CCD, Oxford Diffraction Ltd. Abingdon, Oxfordshire, UK, 2005

23. Crysalis RED, Oxford Diffraction Ltd. Abingdon, Oxfordshire, UK, 2005

30 24. Sheldrick, G. M. (2008). Acta Cryst. A64, 112-122.

25. M. O'Keeffe, M. Eddaoudi, H. L. Li, T. Reineke and O. M. Yaghi, J. Solid State Chem., 2000, 152, 3-20.

26. (a) V. A. Blatov, Ac.Pavlov St. 1, 443011 Samara, Russia, http://www.topos.ssu.samara.ru/, 2004; (b) V. A. Blatov, A. P.

35 Shevchenko and V. N. Serezhkin, J. Appl. Cryst., 2000, 33, 1193. (c) O. V. Dolomanov, A. J. Blake, N. R. Champness and M. Schroder, J. Appl. Crystallogr., 2003, 36, 1283-1284, (d) O. Delgado-Friedrichs, Systre, http://gavrog.sourceforge.net/, March 2009 